\title{
Estudio sobre la funcionalidad turística del patrimonio cultural del municipio de Carmona y estrategias de actuación
}

\begin{abstract}
El Instituto Andaluz del Patrimonio Histórico ha finalizado un estudio sobre el uso turístico del patrimonio cultural y las estrategias de actuación en las ciudades medias andaluzas, tomando como ejemplo el municipio de Carmona (Sevilla). Este trabajo se enmarca dentro de una de las líneas de investigación del IAPH, centrada en materia de turismo en ciudades históricas, y se ha realizado en colaboración con el Ayuntamiento de Carmona y el Grupo de Investigación Turismo, Patrimonio y Desarrollo del Departamento de Geografía Humana de la Universidad Complutense de Madrid, del que es director el catedrático Miguel Ángel Troitiño Vinuesa.
\end{abstract}

El municipio de Carmona encierra un rico y diversificado patrimonio cultural cuya lectura, conservación y utilización requiere de una visión innovadora, dinámica e integradora, que afronte los desafíos culturales, económicos, medioambientales y funcionales que el uso responsable del patrimonio cultural y la presión del turismo plantean. Por su trayectoria reciente de compromiso con la puesta en valor del patrimonio y práctica de concertación entre la administración cultural y turistica, constituye un excelente laboratorio para ensayar una estrategia de actuación que integre patrimonio cultural, urbanismo, paisaje y turismo. Se trata de construir conocimiento para avanzar en una línea de actuación que persigue plantear estrategias operativas que ayuden a integrar patrimonio y turismo en el marco de un proyecto sostenible de desarrollo territorial. En este sentido el estudio y la experiencia desarrollada en Carmona, más allá de su interés como estudio de caso, puede ser de utilidad para otras ciudades medias y territorios andaluces.

Objetivos, metodología y estructura

El estudio realizado se aborda desde un marco de colaboración entre el Ayuntamiento de Carmona (áreas de Turismo y Cultura), el Instituto Andaluz del Patrimonio Histórico, como impulsor del proyecto, y el equipo del Grupo de Investigación Turismo, Patrimonio y Desarrollo de la Universidad Complutense de Madrid como responsable científico. El trabajo persigue responder a las demandas y necesidades del sector turístico y contribuir en la recuperación funcional del patrimonio cultural, partiendo de estrategias de complementariedad y equilibrio. Se ha

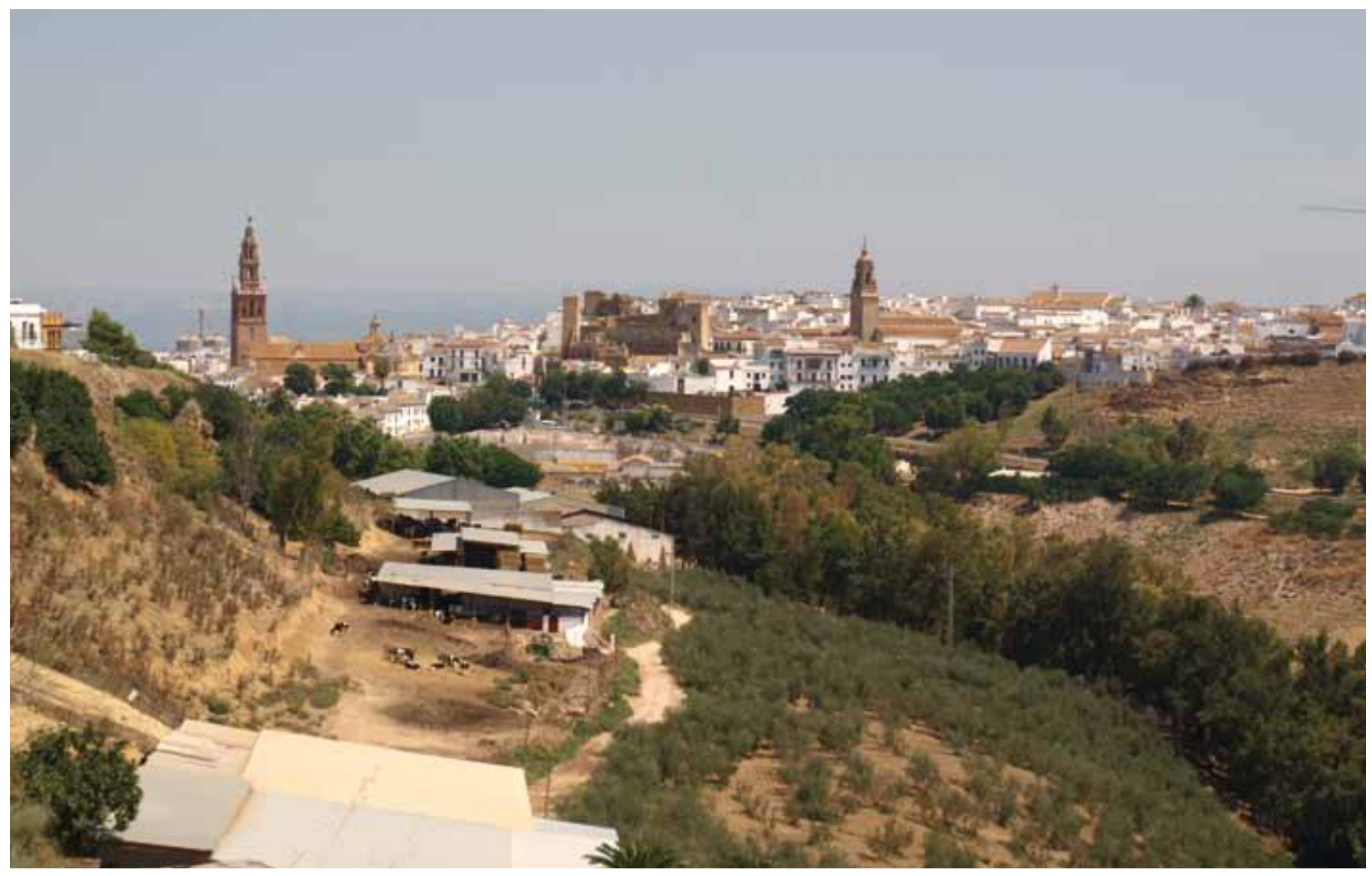

Vista de Carmona desde la cornisa sur de los Alcores. Foto: Libertad Troitiño Torralba 
planteado con una doble preocupación, por un lado, implementar una metodología operativa de inventario que posibilite un conocimiento sistémico de los niveles de funcionalidad turistica de los recursos patrimoniales $y$, por otro, perfilar una estrategia de actuación que contribuya a impulsar acciones de cooperación y concertación. Se trata, en suma, de avanzar en una línea de trabajo de conocimientoacción que ayude en la toma de decisiones, fundamentalmente, a nivel municipal, en cuestiones patrimoniales, turisticas y urbanisticas, para que Carmona incorpore plenamente el patrimonio cultural, uno de sus principales activos, a un proyecto de desarrollo territorial formulado en claves sociales, culturales y medioambientales.

El trabajo se ha articulado de acuerdo a tres fases:

$1^{\text {a }}$ Inventario de la funcionalidad turistica del patrimonio cultural, donde se ha efectuado un análisis y valoración, tomando como referencia fundamental los recursos de valor patrimonial con algún nivel de protección en el Plan Especial de Protección del Patrimonio Histórico de Carmona (2009): 241 elementos patrimoniales, 189 espacios urbanos, 6 unidades de paisaje y 9 recursos de patrimonio inmaterial. Las fichas del inventario y la base de datos elaborada permiten sistematizar y cartografiar la información necesaria para identificar y valorar los niveles de funcionalidad turistica de los diferentes recursos.

$2^{\mathrm{a}}$. Análisis y diagnóstico de la funcionalidad turística de los recursos patrimoniales. Se organiza en cuatro apartados: elementos patrimoniales, espacios urbanos, paisajes y recursos de patrimonio inmaterial. En cuanto a los primeros, se analizan las características y problemáticas básicas (titularidad, estado de conservación, posibilidades de visita, niveles de funcionalidad turistica, dificultades de puesta en valor etc.) y, a continuación, las problemáticas prioritarias según niveles de funcionalidad turística. Los espacios urbanos se caracte-

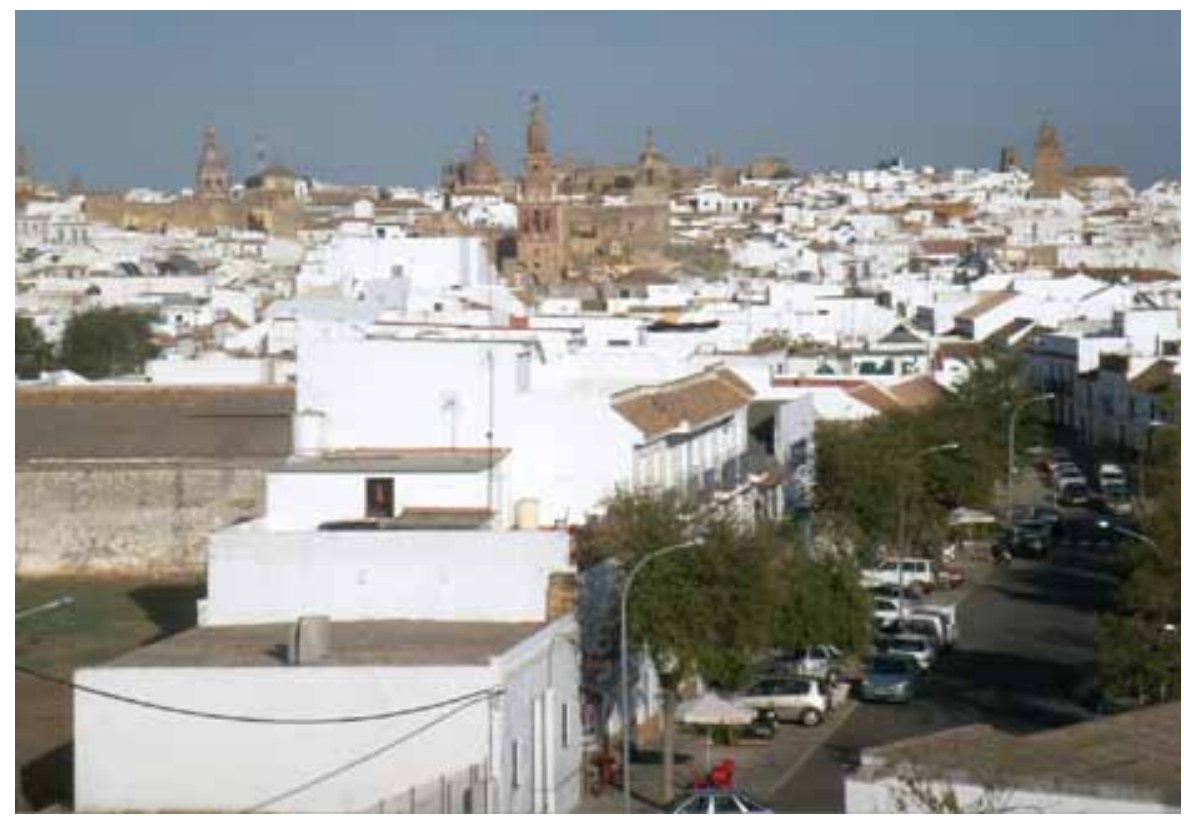

Vista general de Carmona desde la necrópolis romana. Foto: Miguel Ángel Troitiño Vinuesa

rizan en relación con usos predominantes, señalización, usos de la edificación, niveles de funcionalidad turistica y grado de dificultad de puesta en valor. En el paisaje se resaltan los aspectos relevantes de cada una de las seis unidades identificadas y se realiza una valoración de sus niveles de funcionalidad turistica. Respecto al patrimonio inmaterial se identifican y caracterizan los principales recursos, así como su funcionalidad y potencial de aprovechamiento turistico.

$3^{a}$. Estrategias de actuación. Tras un planteamiento general encuadrado en el contexto andaluz, se perfilan, primero, las estrategias generales en el marco de la complementariedad entre patrimonio cultural y turismo, y posteriormente, las bases estratégicas de actuación en cinco niveles: urbanístico/territorial, patrimonial, turistico, patrimonial/turistico y de gestión.

\section{Análisis y diagnóstico de la funcionalidad turística de los recursos patrimoniales}

La potencia patrimonial del centro histórico de Carmona se pone de manifiesto en la presencia de 241 elementos con algún nivel de protección, destacando la existencia de 19 bienes de interés cultural. Del conjunto de elementos, 200 son de titularidad privada, 23 públicos y 18 religiosos; su aceptable estado de conservación -166 en buen estado, 53 en regular, 19 en malo y 3 en ruina- evidencia el esfuerzo de protección y recuperación desarrollado en los últimos años. Una parte limitada de este patrimonio tiene funcionalidad turistica: 5 elementos la tienen principal, 20 secundaria, 35 incidental y 181 son incompatibles con esta función. Sin embargo, una valoración del potencial turistico de los recursos refleja la existencia de 5 recursos de visita obligada, 69 muy interesantes y 88 interesantes. En general, el patrimonio de Carmona adolece de un precario nivel adecuación para la visita turistica; de los cinco elementos con funcionalidad turistica principal sólo tres están realmente puestos en valor (Necrópolis, Puerta Sevilla y Museo de Carmona) y en dos, la dificultad para hacerlo es de tipo medio; de los 20 con funcionalidad turistica secundaria sólo 4 están puestos en valor, siendo la dificultad alta en 3 casos, media en 5 y baja en 9; entre los 33 de naturaleza turística incidental ninguno está puesto en valor, en 13 la dificultad es alta, media en 11 y en 9 baja. 


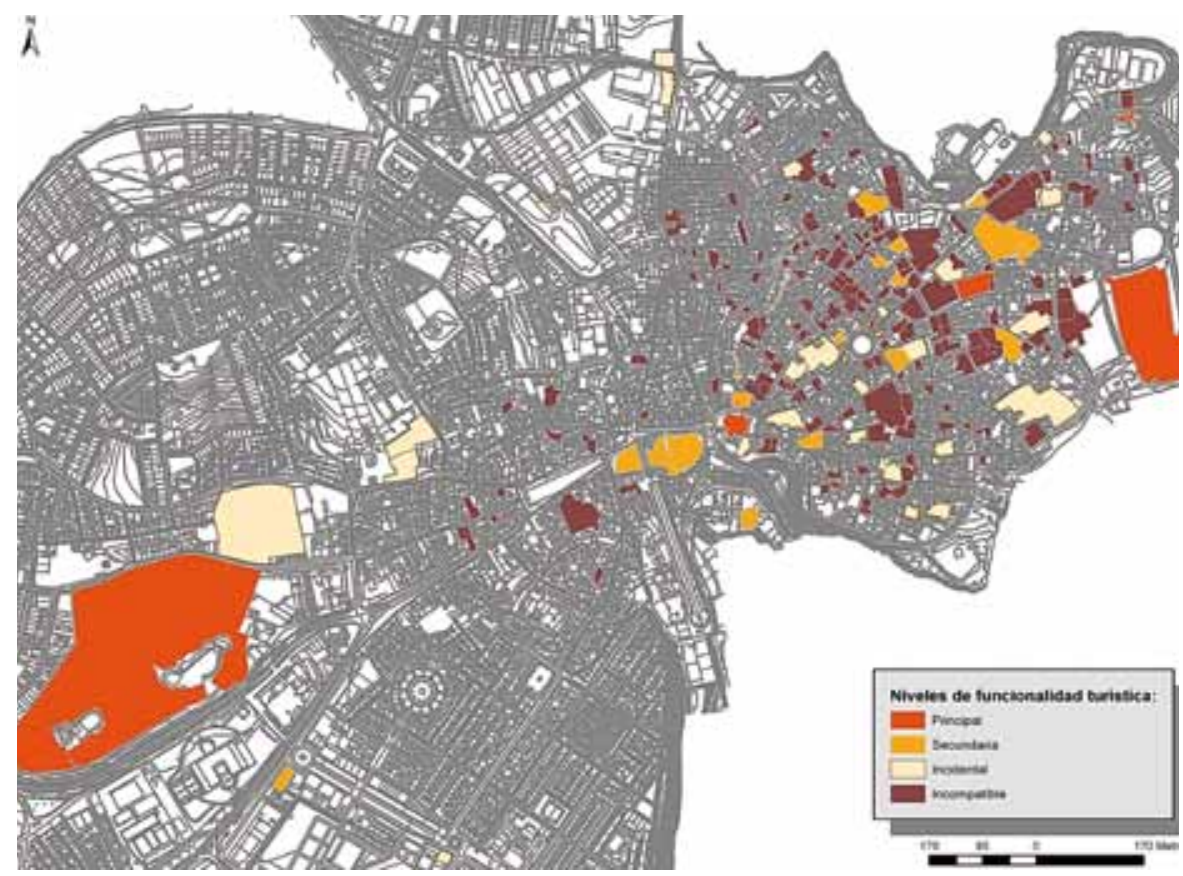

Funcionalidad turística de los elementos patrimoniales. Fuente: Elaboración propia

En los espacios urbanos, el número más elevado corresponde a los de un nivel de funcionalidad turistica incidental, 89, en 73 espacios es de carácter secundario y sólo 27 tienen función turística principal. Están puestos en valor 50 espacios, en 35 la dificultad para hacerlo es baja, en 45 media, en 58 alta y en 1 muy alta.

Objetivar las dimensiones turisticas del paisaje es una tarea nada fácil, dado que la tradición y las prácticas turísticas han llevado a leer el territorio más en clave de hitos y singularidades (monumentos, yacimientos arqueológicos, puentes, singularidades geológicas o botánicas, etc.) que de conjuntos. Para adentrarse en estas problemáticas, pues se trata de un ámbito de innovación a la hora de preparar los territorios para ofertar productos turisticos atractivos, cruzando variables físicas, accesibilidad, densidad patrimonial y visibilidad, se han identificado seis unidades de paisaje: alcores urbano, alcores periurbanos, colinas alberizas, la vega, terrazas del Guadalquivir y llanuras aluviales del Corbones. En el caso de alcores urbano la funcionalidad turistica es secundaria y las dimensiones paisajísticas están débilmente incorporadas y va- loradas en la oferta turística-patrimonial, cuando su atracción es alta y las dificultades de puesta en valor son de tipo medio. En el resto de las unidades la funcionalidad turística es incidental y las dificultades de puesta en valor son altas.

El patrimonio inmaterial de Carmona tiene, fundamentalmente, proyección e interés para la sociedad local, al estar vinculado a sus prácticas religiosas y festivas. En este sentido, resulta lógico que, de los 9 recursos identificados, 8 tengan una funcionalidad turistica incidental y con proyección local o comarcal. Únicamente la Semana Santa, declarada de interés turístico nacional, tiene un considerable atractivo turístico y, en cualquier caso, una funcionalidad turistica de tipo secundario, estrechamente vinculada con el desarrollo de las procesiones en el conjunto histórico.

\section{Estrategias de actuación: Carmona un destino patrimonial integrador}

Carmona se enfrenta al reto de construir el territorio del siglo XXI, donde el patrimonio y la cultura, así como las actividades turísticas y de ocio, deben tener un impor- tante protagonismo. El reto está, por un lado, en diseñar una estrategia de actuación que contribuya a la recuperación activa de un rico y diversificado patrimonio, al que hay que dar sentido y funcionalidad, y, por otro, en consolidarse como un destino patrimonial potente, competitivo y singularizado. Para ello se formula una estrategia transversal, orientada a propiciar la coordinación y la complementariedad entre politicas urbanísticas, patrimoniales y turísticas. A nivel general se apuesta por la identificación y puesta en valor turistico de los principales activos culturales, la difusión territorial de la actividad turistica, la elaboración de estrategias y programas de actuación conjuntos y la cooperación interadministrativa.

Las estrategias especificas, trabajando en clave de sistema patrimonial territorial, apuntan a configurar Carmona como un destino patrimonial integrador. A nivel urbanístico/territorial están orientadas a propiciar una adecuada integración del patrimonio y el turismo en la estructura urbanística, territorial y funcional del municipio, rentabilizando las oportunidades que el patrimonio y el turismo ofrecen para el desarrollo. En este sentido se plantea jerarquizar y priorizar las actuaciones orientadas a poner en valor los activos patrimoniales, la coordinación de actuaciones, impulsar un plan de recuperación de las cornisas del alcor y priorizar las actuaciones urbanisticas que propicien la articulación y complementariedad entre los diferentes ámbitos patrimoniales.

El patrimonio cultural es, sin duda, un recurso básico de Carmona y su ordenación y gestión deben tener presentes las necesidades relacionadas con la funcionalidad turística y también con la cultura y el proyecto urbano. Se perfila una estrategia patrimonial orientada tanto al logro de una adecuada complementariedad con el sector turístico como a rentabilizar las oportunidades que la oferta cultural ofrece para generar actividad económica y renovar la imagen del destino turístico. Para avanzar 


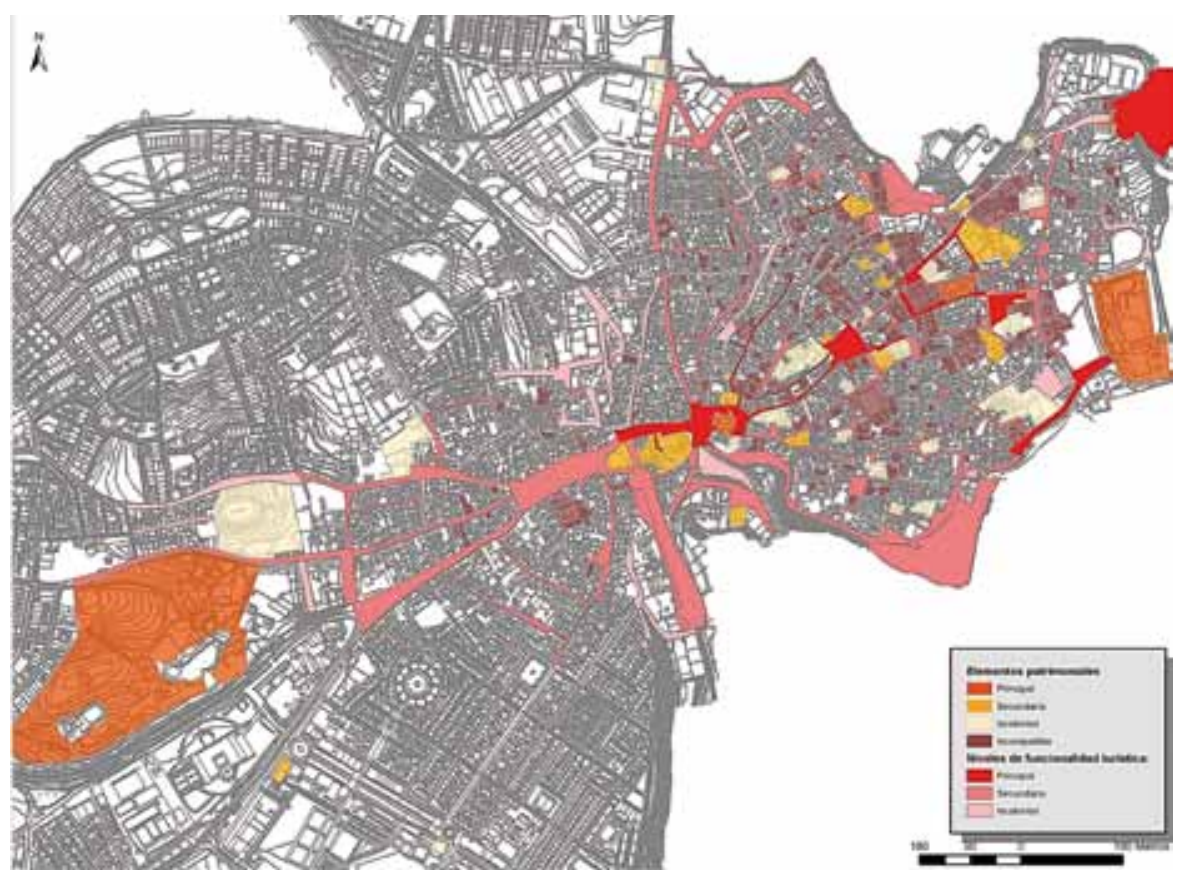

Funcionalidad turística de los espacios urbanos. Fuente: Elaboración propia

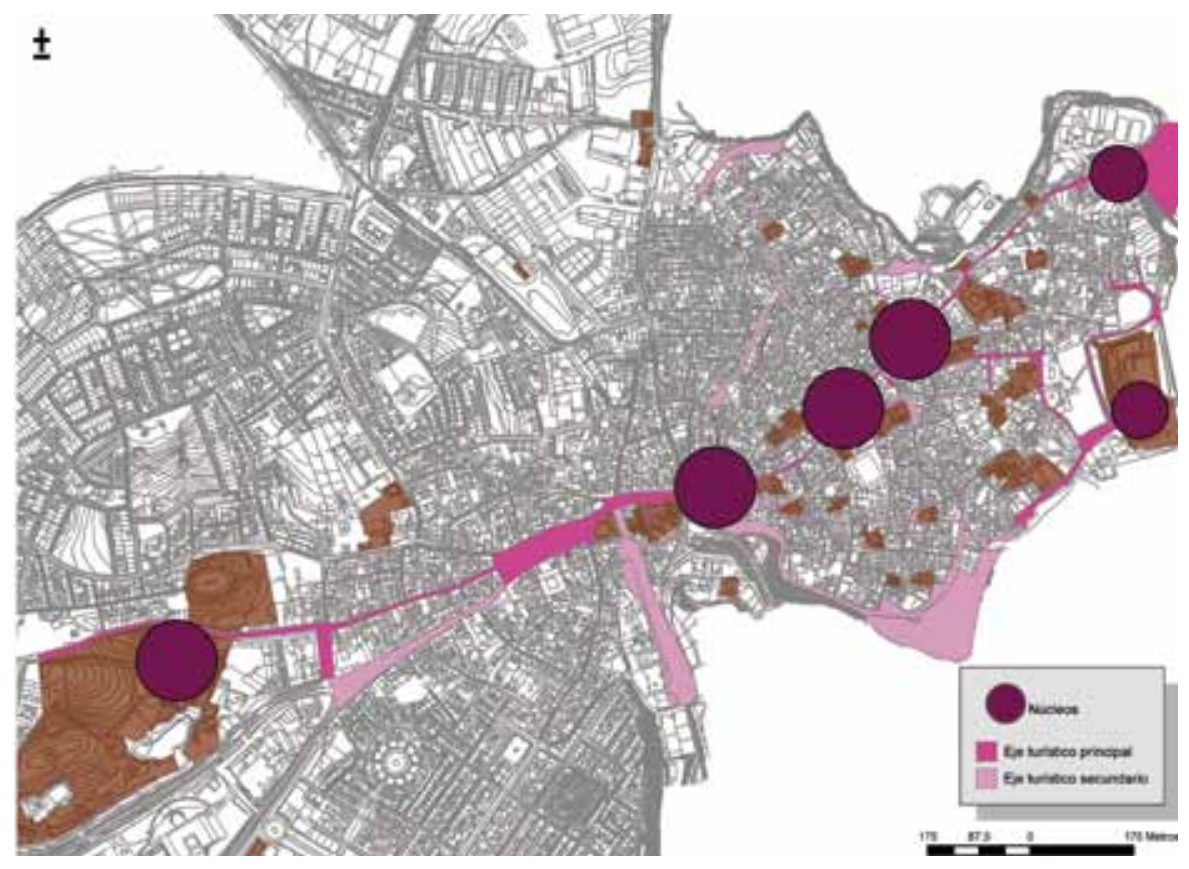

Núcleos y ejes turísticos de Carmona. Fuente: Elaboración propia

se tiene que trabajar con planteamientos de concertación y complementariedad, apuntándose como acciones relevantes: fijar con claridad los niveles y prioridades de intervención, adecuar el patrimonio y sus entornos, impulsar convenios de cooperación, aproximar la gestión cultural y la turistica, reforzar los contenidos asi como la funcionalidad de un centro de interpretación de la ciudad y del territorio.
El atractivo turístico de Carmona se basa en el patrimonio cultural y de ahi que se venga impulsando la candidatura para su inclusión en la Lista del Patrimonio Mundial de la UNESCO, proyecto que de consolidarse propiciaria su proyección como destino patrimonial. La estrategia turistica apuesta por la calidad y la cooperación turistico/patrimonial, desarrollando actuaciones orientadas a diferenciarse, diversificar su oferta, integrar plenamente la actividad turistica en la vida urbana, propiciar la movilidad peatonal, impulsar iniciativas de promoción y comercialización y reforzar los servicios de atención al visitante.

En el marco de la concertación entre estrategias y propuestas de actuación a nivel patrimonial/turístico se formulan propuestas específicas con relación al patrimonio arquitectónico del conjunto histórico y entorno, los espacios urbanos de valor patrimonial, los paisajes, el patrimonio inmaterial, el rural y el arqueológico. Se formula una propuesta especifica orientada a articular y conectar los núcleos clave de la oferta patrimonial/ turistica y propiciar la conexión peatonal y paisajística con los recursos patrimoniales de segundo nivel.

La naturaleza transversal del patrimonio y del turismo plantean la necesidad de introducir cambios en los modelos de gestión, siendo aconsejable superar, por un lado, los enfoques sectoriales $y$, por otro, dar plena entrada a la participación del sector privado y de la ciudadanía. Sin cambios en el modelo de gestión resulta muy difícil avanzar en el sentido que esta estrategia de actuación perfila, de ahí que se contemple trabajar alrededor de diversas líneas de actuación: consorcio interadministrativo, departamento de gestión de la ciudad, consejo de patrimonio, etc.

Las dificultades y los bloqueos para el cambio existen pero, ante las necesidades del siglo XXI, no son muchas las alternativas. Si se quiere conseguir que Carmona sea un destino patrimonial singular y atractivo, no hay otro camino que innovar en la gestión y para ello, desde el liderazgo municipal, es necesario contar con el sector empresarial, el apoyo institucional y la implicación ciudadana.

\section{Miguel Ángel Troitiño Vinuesa Universidad Complutense de Madrid Libertad Troitiño Torralba}

Universidad a Distancia de Madrid 